\title{
On the geology, petrology and physics of making copper porphyries
}

\author{
Cin-Ty LeE ${ }^{1}$, Ming TANG ${ }^{1,2}$, BODA LiU ${ }^{1}$
}

${ }^{1}$ Rice University, TX, USA; ctlee@rice.edu

${ }^{2}$ Peking University, China; mingtang@pku.edu.cn

Porphyry copper deposits (PCDs) are shallow level magmatic intrusions associated mostly with thick ( $>45 \mathrm{~km}$ ) magmatic arcs. However, not only are the $\mathrm{Cu}$ contents of primary arc magmas in these environments unremarkable in terms of $\mathrm{Cu}$, they become depleted in $\mathrm{Cu}$ with differentiation. Here, we show that the formation of PCDs is controlled largely by intra-crustal differentiation, with little influence from the subducting slab. PCDs form when the crust becomes thick enough to stabilize garnet as a fractionating magmatic phase. Because $\mathrm{Fe}^{2+}$ is strongly compatible but $\mathrm{Fe}^{3+}$ is incompatible in garnet, such fractionation depletes Fe from the magma, generating the wellknown calc-alkaline differentiation trend. This depletion in Fe drives sulfide segregation and removal of most of the magma's $\mathrm{Cu}$ into the lower crust in the form of deep-seated cumulates. The residual magma is left with minimal $\mathrm{Cu}$ to make PCDs. However, with progressive garnet fractionation, the remaining $\mathrm{Fe}$ in the magma becomes more oxidized, which oxidizes sulfide to sulfate and releases sulfide bound $\mathrm{Cu}$ into solution. Garnet-driven auto-oxidation of the magma increases the ability of endogenic magmatic fluids to self-scavenge $\mathrm{Cu}$ from large volumes of otherwise $\mathrm{Cu}$-poor magmas and then transport and concentrate $\mathrm{Cu}$ to the tops of magmatic bodies. Scavenging may be facilitated by episodic hydrofracturing of crystal-rich source mushes, the fractures allowing for extensive tapping of these source mushes and rapid upwards transport. CPDs may represent the accumulation over time of numerous episodic hydrofracturing events, each associated with deep-seated magmatic recharge events. 